\section{Direct glucocorticoid receptor-Stat5 interaction in hepatocytes controls body size and maturation-related gene expression}

\author{
David Engblom, ,,7 Jan-Wilhelm Kornfeld, ${ }^{2,7}$ \\ Lukas Schwake, ${ }^{1}$ Francois Tronche, ${ }^{1,3}$ \\ Andreas Reimann, ${ }^{4}$ Hartmut Beug, ${ }^{5}$ \\ Lothar Hennighausen, ${ }^{6}$ Richard Moriggl, ${ }^{2,8,10}$ \\ and Günther Schütz ${ }^{1,8,9}$
}

\begin{abstract}
${ }^{1}$ Division of Molecular Biology of the Cell I, German Cancer Research Center, D-69120 Heidelberg, Germany; ${ }^{2}$ Ludwig Boltzmann Institute for Cancer Research, A-1090 Vienna, Austria; ${ }^{3}$ Centre National de la Recherche Scientifique UMR7148, Collège de France, F-75231 Paris Cedex 05, France; ${ }^{4}$ Centre National de la Recherche Scientifique FRE 2850, Department of Developmental Biology, Pasteur Institute, F-75014 Paris, France; ${ }^{5}$ Institute of Molecular Pathology, A-1030 Vienna, Austria; ${ }^{6}$ National Institute of Diabetes and Digestive and Kidney Diseases, National Institutes of Health, Bethesda, Maryland 20892, USA
\end{abstract}

The glucocorticoid receptor regulates transcription through DNA binding as well as through cross-talk with other transcription factors. In hepatocytes, the glucocorticoid receptor is critical for normal postnatal growth. Using hepatocyte-specific and domain-selective mutations in the mouse we show that Stat5 in hepatocytes is essential for normal postnatal growth and that it mediates the growth-promoting effect of the glucocorticoid receptor through a direct interaction involving the $\mathrm{N}$ terminal tetramerization domain of Stat5b. This interaction mediates a selective and unexpectedly extensive part of the transcriptional actions of these molecules since it controls the expression of gene sets involved in growth and sexual maturation.

Supplemental material is available at http://www.genesdev.org.

Received January 24, 2007; revised version accepted March 16, 2007.

Glucocorticoids are secreted by the adrenal cortex and constitute the final effector of the hypothalamus-pituitary-adrenal (HPA) gland axis. They are essential for the maintenance of homeostasis during environmental challenges and are also required for normal development and survival. The effects of glucocorticoids are mediated by the ubiquitously expressed glucocorticoid receptor (GR)

[Keywords: Somatomedin; liver; Cre-loxP; growth hormone; microarray] ${ }^{7}$ These authors contributed equally to this work.

${ }^{8}$ These authors contributed equally to this work.

Corresponding authors.

9E-MAIL g.schuetz@dkfz-heidelberg.de; FAX 49-6221-423470.

${ }^{10}$ E-MAIL richard.moriggl@lbicr.lbg.ac.at; FAX 43-14277-9641.

Article is online at http://www.genesdev.org/cgi/doi/10.1101/gad.426007. and the mineralocorticoid receptor that has a restricted expression. Upon ligand binding, the GR can act in a multitude of ways to induce or repress the transcription of target genes. These ways include binding to glucocorticoid response elements (GREs) in regulatory gene regions and protein-protein interactions with other transcription factors. DNA binding of the GR is believed to mediate most of the activating actions while cross-talk with transcription factors is believed to mediate the repressing actions (Reichardt et al. 1998, 2001). One exception, in which GR activates transcription without classic DNA binding, is its functional interaction with Stat5 (Stocklin et al. 1996). It was originally described for activation of the $\beta$-casein promoter, where the activation was shown to depend on physical GR-Stat5 interaction and DNA binding of Stat5, whereas GR binding to a classic GRE was dispensable (Stoecklin et al. 1997). In addition, it has been reported that Stat5 can inhibit glucocorticoid-mediated activation of GREs (Stocklin et al. 1996; Biola et al. 2001). However, these studies (Stocklin et al. 1996; Stoecklin et al. 1997; Biola et al. 2001) were carried out in vitro and only investigated the behavior of a few Stat5 target genes.

We recently showed that deletion of $N r 3 c 1$, the gene encoding GR in hepatocytes leads to a defect in postnatal growth (Tronche et al. 2004). Since Stat5 is a critical link in growth hormone $(\mathrm{GH})$ signaling, it was suggested that this growth deficiency may depend on abrogated Stat 5 signaling. Hepatocyte-specific deletion of the genes encoding GR resulted in reduced expression levels of some Stat5 targets regulated by $\mathrm{GH}$, such as insulin-like growth factor-1 (IGF-1) and the acid-labile subunit (ALS) (Tronche et al. 2004). Further, GR and Stat5 were shown to physically interact in the liver, and GR was demonstrated to be present on Stat5-dependent regulatory regions of the genes for IGF-1 and ALS. Collectively, this may indicate that GR in hepatocytes is necessary for $\mathrm{GH}$-induced postnatal growth. However, this is not in agreement with the hypothesis that the growth-promoting effects of $\mathrm{GH}$ are mediated by local production of IGF-1 in target organs such as bone, cartilage, or muscles and that $\mathrm{GH}$ action in liver cells is dispensable (Isaksson et al. 1982; Sjogren et al. 1999; Yakar et al. 1999). Interestingly, a recent study has, again, postulated that the hepatocytes are crucial for growth (Yakar et al. 2002). It is questionable whether the dwarfism observed in hepatocyte-specific GR mutants is exclusively Stat5 dependent or if it is due to other disorders such as metabolic disturbances that could be Stat 5 independent. To address whether GH signaling in the liver is necessary for postnatal growth and whether this signaling involves Stat5GR interactions, we generated mice with hepatocytespecific deletions of GR and/or Stat5.

We show that Stat5-GR protein-protein interaction in hepatocytes is critical for normal postnatal growth and that Stat5-GR interactions are responsible for the activation of a specific, and substantial, part of the target genes of GR and Stat5. Using biochemical and genetic methods as well as expression profiling, we also show that the $\mathrm{N}$ terminus of Stat $5 \mathrm{~b}$ is necessary for GR-Stat5 interactions in the liver. These data shed new light on the long-lasting discussion concerning the role of hepatocytes in postnatal growth and show an unexpectedly broad role for the interaction of GR and Stat5. 


\section{Results and Discussion}

In order to assess the importance of Stat5 in hepatocytes for postnatal growth, we generated mice lacking Stat5 selectively in hepatocytes. We crossed mice carrying the Cre-recombinase under control of the albumin promoter and the albumin and $\alpha$-fetoprotein enhancers with mice in which the Stat5 locus, containing both Stat5a and Stat5b, was flanked by loxP sites (Kellendonk et al. 2000; Cui et al. 2004). The resulting mutants (Stat5 ${ }^{\text {AlfpCre }}$ ) displayed normal growth up to 2-3 wk of age. After weaning at $3 \mathrm{wk}$ they showed severe growth retardation (Fig. 1). We compared the growth of these mice with that of mice lacking GR in hepatocytes (GR $\left.{ }^{\text {AlfpCre }}\right)$. Interestingly the $\mathrm{GR}^{\text {Alf-pCre }}$ mice showed growth curves identical to the Stat $5^{\text {AlfpCre }}$ mice during postnatal development (Fig. 1). To investigate whether Stat5 mediates the growth effect of GR, we also generated mice lacking both GR and Stat5 in hepatocytes. These mice (Stat5/GR AlfpCre) show identical growth curves to each of the single mutants, indicating that the growth-promoting role of GR is mediated through Stat5.

To elucidate possible similarities between the Stat5 and GR target genes on the genome-wide level, we compared transcription profiles from livers taken from control mice with profiles from livers taken from Stat5 $5^{\text {AlfpCre }}$ and GRAlfpcre mice. We used three Affymetrix MGU74Av2 arrays, containing $>12,000$ probe sets, for each mutant group and nine arrays for the control group. RNA from three livers was pooled on each array (for details, see Materials and Methods). Interestingly, the genes significantly down-regulated by loss of Stat 5 and GR overlap to a high extent (significant change defined as $p<0.001$, or both $p<0.0025$ and fold change $>2 /<0.5$ ) (Fig. 2A). Thus, $42 \%$ of the genes found to be down-regulated in the GR AlfpCre mice were also down-regulated in the Stat $5^{\text {AlfpCre }}$ mice. Correspondingly, $26 \%$ of the genes down-regulated in the Stat $5^{\text {AlfpCre }}$ mice were also downregulated in the $\mathrm{GR}^{\mathrm{AlfpCre}}$ mice. The genes significantly dependent on both the GR and Stat5 are listed in Table 1; the genes significantly changed in any of the mutants used in this study are listed in Supplementary Table 1 together with all genes that showed $p<0.01$. The high overlap was in the same range if less stringent criterions were used $(p<0.005$ or $p<0.01)$ (Supplementary Table 2). The genes up-regulated in both mutants were far less abundant (Fig. 2A).

To validate the change of these genes we further assessed their expression level in Stat5/GR ${ }^{\text {AlfpCre }}$ double-
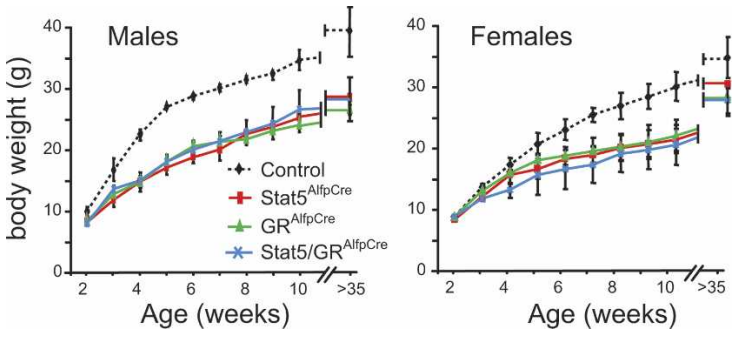

Figure 1. Growth deficiency in Stat $5^{\text {AlfpCre }}, \mathrm{GR}^{\text {AlfpCre }}$, and Stat5/ $\mathrm{GR}^{\text {AlfpCre }}$ mice. Growth curves from control mice (black dashed line), mice lacking Stat5 in the hepatocytes (red line), mice lacking GR in hepatocytes (green line), and mice lacking both Stat5 and GR in hepatocytes (blue line). All mutants show a very similar growth defect starting around $3 \mathrm{wk}$. Error bars indicate standard error of the mean.

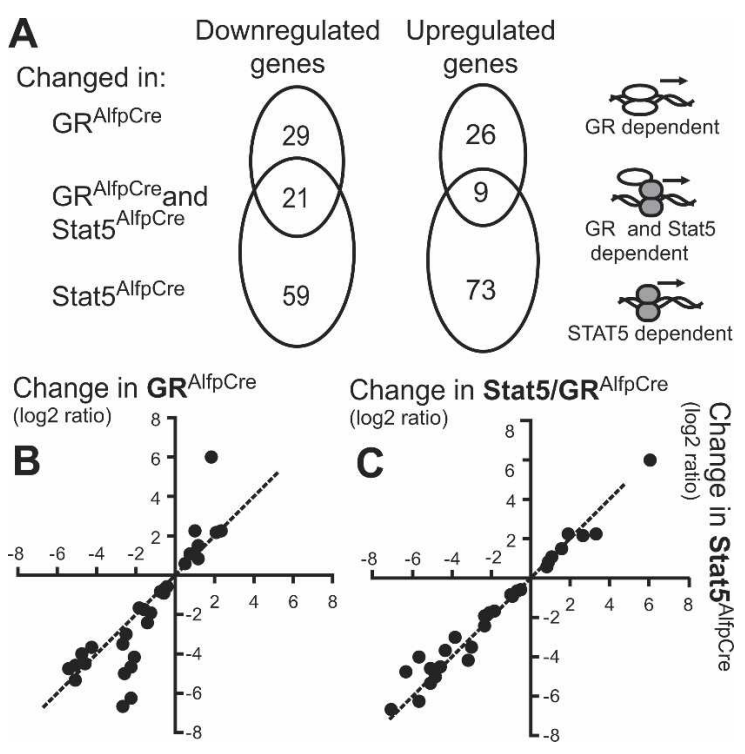

Figure 2. Substantial similarities in expression profiles from Stat5 ${ }^{\text {AlfpCre }}, \mathrm{GR}^{\text {AlfpCre, }}$, and Stat5/GR $\mathrm{GlfpCre}^{\text {mice. }}(A)$ Venn diagrams showing overlap of genes significantly changed in livers from mice with hepatocyte-specific deletion of Stat5 or GR. As criterion for calling a gene significantly changed we used $p<0.001$, or the combined criterion of $p<0.0025$ and a $\log$ ratio $>1$ or less than -1 (fold change $>2$ or $<0.5)$. Note the substantial overlap of genes downregulated by the two mutations. $(B)$ Comparison between Stat $5^{\text {AlfpCre }}$ and $\mathrm{GR}^{\text {AlfpCre }}$ mutants of the expression changes for genes significantly changed in both mutants. All of these genes are changed in the same direction in the two mutants and the magnitude of change correlates tightly. (C) Comparison of expression changes in Stat 5 mutant and Stat5 + GR mutant livers for the same genes as in $B$. There is no additional effect of deleting GR in the absence of Stat5 for the expression levels of these genes.

mutant mice. As expected, the genes that were significantly changed in the same direction in both Stat 5 AlfpCre and GR ${ }^{\text {AlfpCre }}$ mice were also changed in the same direction in the Stat5/GR AlfpCre double-mutant mice (Table 1A; Supplementary Table 2). Further, six genes were tested with quantitative PCR and they were all found to be significantly different from controls in all genotypes (Supplementary Table 2).

The extensive overlap between the expression changes induced by the two single-deletion mutants may be explained either by a direct functional interaction between these transcription factors or by an independent regulation of the same set of genes. If there is a direct physical interaction, the magnitude of change of the individual genes should correlate between the two mutants, so that a gene with a given fold change in one mutant should have a similar fold change in the same direction in the other mutant. In contrast, if the actions are independent this should not be the case. To address this issue, we plotted the average log ratios of the genes identified as significantly changed in both mutants against each other (Fig. 2B). This revealed that genes changed in both mutants were always changed in the same direction, indicating the presence of a "positive" interaction. The lack of genes changed in opposite directions suggests that during basal conditions Stat5 repression of GRE-containing promoters is not a common mechanism in the liver. We also found that the magnitudes of expression changes were highly correlated between the mutants (Fig. 2B). Contrasting to the general trend, a small group of genes 
Downloaded from genesdev.cshlp.org on April 26, 2023 - Published by Cold Spring Harbor Laboratory Press

Table 1. Genes and functional groups of genes that are regulated by Stat5-GR interactions

(A) Individual genes

\begin{tabular}{|c|c|c|c|c|c|c|}
\hline \multicolumn{2}{|l|}{ Down in GR ${ }^{\text {AlfpCre }}$ and Stat5 $5^{\text {AlfpCre }}$} & Stat $5^{\text {AlfpCre }}$ & $\mathrm{GR}^{\mathrm{AlfpCre}}$ & Stat5 $5^{\text {AlfpCre }} / \mathrm{GR}^{\text {AlfpCre }}$ & Stat $5^{\Delta \mathrm{N}}$ & \multirow[b]{2}{*}{ Functional set } \\
\hline \multicolumn{2}{|l|}{ Gene name } & \multicolumn{4}{|c|}{ Changes (log2 ratios) } & \\
\hline IGF-binding protein, acid labile subunit & Igfals & -6.7 & -2.6 & -7.1 & -1.9 & $\mathrm{~s}, \mathrm{~g}$ \\
\hline Insulin-like growth factor 1 & Igfl & -6.3 & -2.2 & -5.7 & -1.1 & $\mathrm{~s}, \mathrm{~g}$ \\
\hline Epidermal growth factor receptor & Egfr & -5.3 & -5.1 & -5.1 & -5.4 & $\mathrm{~g}, \mathrm{~m}$ \\
\hline Cysteine sulfinic acid decarboxylase & Csad & -5.0 & -2.6 & -4.8 & -3.3 & $\mathrm{~g}$ \\
\hline Hydroxysteroid dehydrogenase- 5 & Hsd3b5 & -4.8 & -5.5 & -6.3 & -4.0 & $\mathrm{~g}, \mathrm{~m}, \mathrm{~d}$ \\
\hline Suppressor of cytokine signaling 2 & Socs2 & -4.6 & -5.1 & -5.1 & -2.8 & $\mathrm{~g}$ \\
\hline Peroxiredoxin 4 & $\operatorname{Prdx} 4$ & -4.5 & -4.6 & -4.6 & -3.6 & \\
\hline DNA segment, human D4S114 & D0H4S114 & -4.2 & -2.1 & -3.2 & -2.5 & \\
\hline Serine proteinase inhibitor A3K (SPI2) & Serpina3k & -3.5 & -2.7 & -3.0 & -2.5 & $\mathrm{~g}$ \\
\hline Flavin-containing monooxygenase 3 & Fmo3 & -3.0 & -2.5 & -3.8 & -3.6 & \\
\hline Hydroxysteroid $17 \beta$ dehydrogenase 2 & Hsd17b2 & -2.4 & -1.4 & -2.3 & -0.9 & $\mathrm{~d}$ \\
\hline Hydroxysteroid dehydrogenase-2 & Hsd3b2 & -1.8 & -1.6 & -2.1 & -0.9 & $\mathrm{~d}$ \\
\hline$\zeta$-chain-associated protein kinase & Zap70 & -1.7 & -1.8 & -1.8 & -0.6 & \\
\hline Acidic ribosomal phosphoprotein P0 & Arbp & -0.9 & -0.6 & -0.9 & -0.4 & \\
\hline Leukemia inhibitory factor receptor & Lifr & -0.8 & -0.8 & -1.0 & -1.0 & \\
\hline Cytochrome P450, 4f 13 & Суp4f13 & -0.7 & -0.5 & -0.7 & -0.1 & \\
\hline Ribosomal protein L27a & Rp127a & -0.6 & -0.4 & -0.5 & -0.3 & $\mathrm{r}$ \\
\hline
\end{tabular}

(B) Groups of genes

\begin{tabular}{ll|lc}
\hline Down in GR & AlfpCre and Stat5 ${ }^{\text {AlfpCre }}$ & Up in GR & AlfpCre and Stat5 $5^{\text {AlfpCre }}$ \\
\hline Somatomedin (IGF-1/ALS) & 0 & Genes repressed by GH & 0 \\
GH-responsive genes & 0 & Fatty acid metabolism & 0.02 \\
Ribosomal proteins (Rpl/Rps) & 0 & Down in Stat5 & AlfpCre \\
Male predominant genes & 0.003 & IFN- $\gamma$ dependent genes \\
Steroid dehydrogenase & 0.015 & Immune response & 0 \\
& & Acute-phase response & 0 \\
& & & 0 \\
\hline
\end{tabular}

(A) Genes significantly down-regulated in both Stat5 ${ }^{\text {AlfpCre }}$ and GR $^{\text {AlfpCre }}$ mice. Expression changes are expressed as log2 ratios of fold changes. If the gene belongs to any of the significantly changed gene sets (see B) it is indicated in the far right column. (s) Somatomedin; (g) GH responsive; (m) male predominant; (d) steroid dehydrogenase; $(\mathrm{r})$ ribosomal protein.

(B) Functional gene sets in which changed genes are enriched, determined using the MAPPfinder software.

were clearly less affected in the GR mutants, indicating that the Stat5 action on these Stat5-dependent promoters is not totally codependent on GR. To further validate the interpretation of these data, we plotted the expression changes of the coregulated genes in double-mutant Stat5/GR AlfpCre mice versus Stat5 ${ }^{\text {AlfpCre }}$ mice (Fig. 2C). This clearly shows that GR is not able to regulate the coregulated genes in the absence of Stat5, indicating that the activating effect of GR on these promoters is entirely mediated by an interaction with Stat5. Collectively, these findings give strong support for a model in which GR and Stat5 activate gene expression of a subset of genes through a direct interaction with each other.

Next, we asked which functional groups of genes are regulated by GR-Stat5 interactions in the liver. To find gene groups with coordinated changes we used the MAPPfinder software (Doniger et al. 2003). This approach can find low-amplitude changes common to many genes in a functional group. We found that the GR-Stat5 interaction is important for many gene sets related to growth and maturation of the organism, such as male-predominant genes, GH-responsive genes, ste- roid dehydrogenases, somatomedin mediators (IGF-1 and ALS), and ribosomal protein genes. The gene sets "genes repressed by $\mathrm{GH}^{\prime}$ and "fatty acid metabolism" were induced in GR and Stat5 mutants. In addition, genes related to the immune response were highly induced in Stat5 ${ }^{\text {AlfpCre }}$ but not in GR ${ }^{\text {AlfpCre }}$ mice (Table 1). As indicated in Table 1, we found an extensive overlap between the genes found to be GR and Stat5 dependent in this study and genes previously found to be changed by various truncations of the GH receptor (Rowland et al. 2005). The changes in male-predominant gene expression are in line with studies from the Waxman group (Udy et al. 1997; Clodfelter et al. 2006) showing sex-specific gene expression in the liver to be GH triggered and Stat 5 dependent.

To elucidate the molecular mechanism of GR-Stat5 interaction we studied livers from mice in which the $\mathrm{N}$ terminus of Stat5 was deleted (Stat $5^{\Delta \mathrm{N}}$ mice). The Nterminal domain of Stat5 is important for tetramerization of two Stat5 dimers (Moriggl et al. 2005). The Stat $5^{\Delta \mathrm{N}}$ mice were originally believed to be completely devoid of Stat5 activity (Teglund et al. 1998), but it is now clear that they have significant expression of $\mathrm{N}$ - 
terminally truncated Stat 5 protein, described in detail recently (Hoelbl et al. 2006; Yao et al. 2006). We further studied the Stat $5^{\Delta \mathrm{N}}$ mice, because they display growth retardation very similar to the mice with hepatocytespecific GR or Stat5 deletion (Tronche et al. 2004). We found that Stat $5^{\Delta \mathrm{N}}$ mice showed $30 \%-40 \%$ Stat $5 \mathrm{~b}$ expression in the liver compared with control mice (Fig. 3A). Thus, these mice are a viable physiologic mouse model for studying the loss of the N-terminal Stat5b domain in liver cells. We did not detect significant amounts of truncated Stat5a proteins (data not shown), although the mutation has been shown to result in such proteins in other tissues. This is likely dependent on the fact that the level of Stat5a in the liver is very low, which also may explain why deletion of Stat5b, but not Stat5a, disturbs postnatal growth. GH administration to control and $S$ tat $5 b^{\Delta N}$ mice showed that Stat $5 b^{\Delta N}$ was tyrosinephosphorylated to a similar extent as full-length Stat5b (Fig. 3A). Also, GR AlfpCre mice show normal tyrosine phosphorylation of Stat5b upon GH stimulation.

To determine whether Stat $5 b^{\Delta N}$ proteins have the ability to bind DNA we performed DNA-binding assays. Stat $5 b$ as well as Stat $5 b^{\Delta N}$ bound strongly to a Stat5specific $\beta$-casein promoter element in a GH-inducible manner (Supplementary Figure 1A). Next, we assessed the chromatin-binding ability of $\mathrm{N}$-terminally truncated
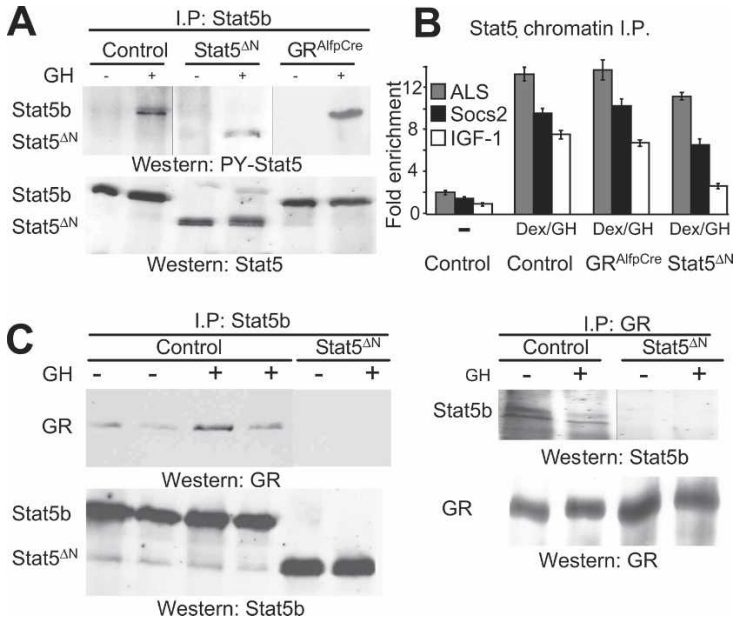

Figure 3. GR-Stat5 interaction is dependent on the Stat $5 \mathrm{~b} \mathrm{~N}$ terminus. $(A$, top $)$ Liver extracts were prepared from untreated or $\mathrm{GH}$ injected mice, followed by quantitative $\alpha$-Stat $5 \mathrm{~b}$ immunoprecipitation (I.P.) and subsequent immunoblotting with anti-P-Y-Stat5 antiserum. (Bottom) Blots were stripped and reprobed with antiStat $5 \mathrm{~b}$-specific antiserum. Stat $5 \mathrm{~b}$ and $S t a t 5 \mathrm{~b}^{\Delta \mathrm{N}}$ proteins are fully tyrosine-phosphorylated upon GH stimulation. The amounts of total Stat $5 \mathrm{~b}$ were reduced to $\sim 40 \%$ in Stat $5^{\Delta \mathrm{N}}$ mice. $(B)$ In vivo binding of Stat5 in proximal enhancers of ALS, Socs2, and IGF-1. The fold enrichment for each DNA fragment upon immunoprecipitation by anti-Stat 5 followed by quantitative PCR is illustrated as histograms (mean \pm SEM). Upon GH stimulation, wild-type Stat $5 b$ is highly bound to chromatin. Stat $5 \mathrm{~b}^{\Delta \mathrm{N}}$ displays $\sim 50 \%-70 \%$ of the DNAbinding capacity of full-length Stat5b. $(C)$ The $\mathrm{N}$ terminus of Stat5b is essential for the GR-Stat5b interplay. Reciprocal immunoprecipitation of liver extracts using anti-Stat5b (left) or anti-GR (right) antisera. (Left) Stat $5 b^{\Delta \mathrm{N}}$ as well as full-length Stat5b proteins are efficiently immunoprecipitated with anti-Stat5b antisera (bottom), but only wild-type Stat5b interacts with the GR as shown via co-IP experiments (top). (Right) GR proteins are comparably pulled down (bottom), but only full-length Stat5b is coimmunoprecipitated (top). Four similar experiments were performed and one representative analysis is shown.
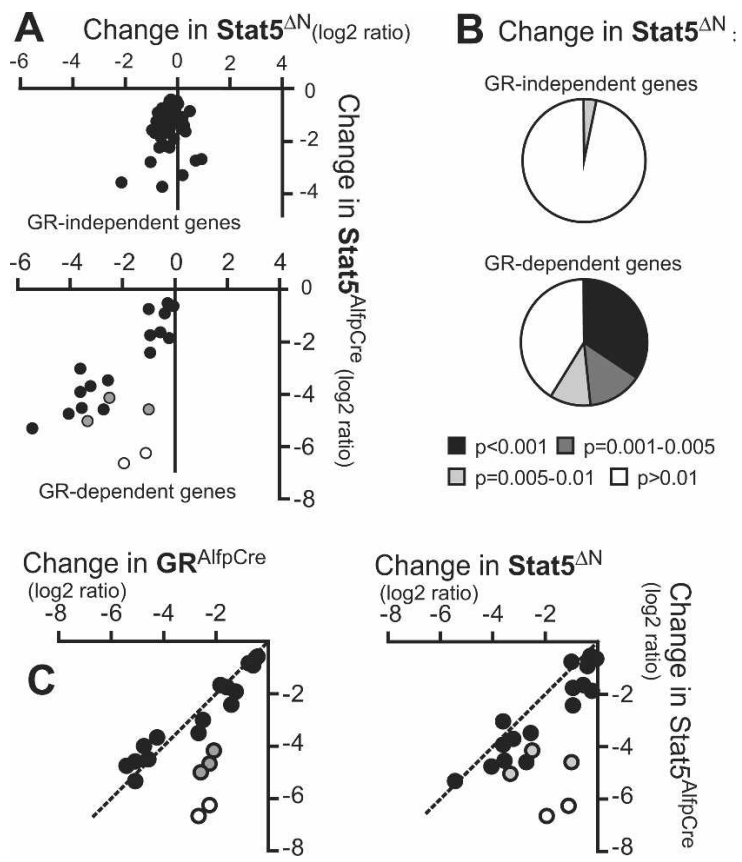

Figure 4. Deletion of the Stat $5 \mathrm{~N}$ terminus selectively reduces the expression of the Stat5-responsive genes, which are also dependent on GR. $(A, B)$ Magnitude $(A)$ and significance $(B)$ of expression changes of GR-independent (top panel) and GR-dependent (bottom panel) Stat5-responsive genes in livers from mice with a deletion of the $\mathrm{N}$ terminus of Stat5. The Stat5-responsive genes that are not dependent on GR show very little dependence on the $\mathrm{N}$ terminus while many of the Stat5-responsive genes also dependent on GR show severely reduced expression levels. $(C)$ Comparison within the group of GR-dependent Stat5 targets. The genes that are only partially GR dependent (white and gray dots; left panel) are also only partially dependent on the $\mathrm{N}$ terminus of Stat5 (right panel).

Stat $5 b^{\Delta N}$ protein to some of the Stat5 target genes identified in expression profiling known to be GH triggered. Chromatin immunoprecipitation (ChIP) experiments were performed using three Stat5-responsive DNA elements (from the genes encoding ALS, IGF-1, and SOCS2) (Supplementary Figure 1B). GH triggered significant binding of Stat $5 \mathrm{~b}$ as well as Stat $5 \mathrm{~b}^{\Delta \mathrm{N}}$ proteins to the specific Stat $5 b$ response regions. N-terminally truncated Stat $5 b^{\Delta \mathrm{N}}$ proteins displayed $\sim 50 \%-70 \%$ binding capacity to these chromatin regions as compared with full-length Stat5b proteins (Fig. 3B). To determine whether the $\mathrm{N}$ terminus of Stat5 is essential for GR protein binding, we performed immunoprecipitation (IP) experiments (Fig. 3C). Coimmunoprecipitation (co-IP) with GR- or Stat5bspecific antisera revealed Stat5-GR protein interaction in both directions. However, the co-IP of Stat5b and GR was lost in Stat $5 b^{\Delta N}$ mice. Thus, we conclude that the Stat5b N terminus is the docking platform for GR.

Analysis of the expression profiles of livers from Stat $5^{\Delta \mathrm{N}}$ mice showed that some of the genes previously identified as Stat5-responsive were expressed at normal levels in the mutant while some were down-regulated. Strikingly, most genes that were dependent on Stat 5 but not GR were unchanged in the Stat $5^{\Delta \mathrm{N}}$ mice (Fig. 4A,B; Supplementary Table 2). In contrast, most of the genes dependent on both GR and Stat5 proteins showed compromised expression levels in Stat $5^{\Delta \mathrm{N}}$ mice. In line with this, Stat5-responsive genes that were only partially GRdependent were also only partially dependent on the $\mathrm{N}$ - 
terminal domain of Stat5b (Fig. 4C). Collectively, this strongly supports the conclusion that the $\mathrm{N}$ terminus of Stat5 is important for the interaction of Stat 5 and GR in vivo and that the overlapping expression changes observed in this study is due to a direct physical interaction between GR and Stat5.

The findings of this study show a critical role for GRStat5 interactions in postnatal growth and maturationrelated gene expression. The hypothesis that this functional interaction is direct and physical is supported by the following results: (1) an extensive overlap of expression changes induced by the loss of GR and Stat5; (2) a tight correlation of the magnitude of changes for coregulated genes between the Stat5 ${ }^{\text {AlfpCre }}$ and GR ${ }^{\text {AlfpCre }}$ mice; (3) the fact that loss of both GR and Stat5 did not affect growth or expression of the coregulated genes more than loss of Stat5 only; and (4) the fact that an N-terminal deletion of Stat5, which disrupts protein-protein interaction with GR, leads to growth retardation and results in abrogated expression preferentially of those Stat5-responsive genes that are also dependent on GR. This is further supported by our previous data, showing that GR is present on Stat5-dependent regulatory regions of GHinduced genes and that mice with a mutation in the dimerization domain of GR, which abrogates DNA binding of GR, display normal growth and intact transcription of GH-responsive genes (Tronche et al. 2004). Collectively, these data support a model where GH-activated Stat5 binds DNA and uses GR as a cofactor to induce growth promoting gene transcription.

The results of this study have a clear implication for the long-standing discussion on the role of the liver in postnatal growth. According to the original "somatomedin hypothesis" GH triggers the hepatocyte to secrete a secondary mediator (later suggested to be IGF-1) promoting postnatal growth. This hypothesis was later contradicted since it was shown that local injections of $\mathrm{GH}$ promotes growth (Isaksson et al. 1982) and that hepatocyte-specific deletion of $I g f-1$ does not cause any major growth disturbances (Sjogren et al. 1999; Yakar et al. 1999). Very recently, it was also shown that mice with a muscle-specific deletion of Stat5 show an $\sim 20 \%$ reduction in growth. (Klover and Hennighausen 2007). However, Yakar et al. (2002) showed that mice lacking ALS in all cells and IGF-1 in hepatocytes display blunted growth. This suggested a role of the hepatocyte in somatic growth, although the conclusions of the study are somewhat limited since the ALS expressed in nonhepatic sites, such as in the developing cartilage /Chin et al. 1994), was also deleted and the additional effect of IGF-1 deletion on general body growth was small and transient. We provide unequivocal evidence for the importance of Stat5 and GR in hepatocytes for postnatal growth. Thus, GH likely triggers growth both through endocrine factors secreted by the liver and through paracrine mediators produced in the target organs. In the study by Yakar et al. (2002), the blunted growth of the ALS/IGF-1 double-mutant mice was suggested to result from the fact that they had even lower levels of circulating IGF-1 than the liver-specific IGF-1 mutants. However, the growth disturbance of the mice in this study is likely dependent on additional GH-target genes, with actions different from regulating the levels of circulating IGF-1. Thus, the IGF-1 level in serum is only moderately reduced in the growth-retarded GR mutants $(28 \%$ reduction; Tronche et al. 2004), while it is much lower in liver-specific IGF-1 mutants (75\% reduction), which show no overt growth defect. This suggests that some of the other genes found to be dependent on GR-Stat5 interactions in this study are actively involved in growth promotion. Identification of those additional hepatic GH-induced mediators of growth remains to be done and will probably be challenging since simultaneous and hepatocyte-specific deletion of three or more genes might be necessary.

The second major finding of this study is the unexpectedly high fraction of transcriptional activation mediated by GR and Stat 5 that is dependent on their interaction with each other (42 and $26 \%$, respectively). We also show that GR is not simply a general positive modulator of Stat5 action since the Stat5-responsive genes are divided in relatively clear sets of GR-dependent and GRindependent genes. Interestingly, these sets fall into different functional groups. Thus, the genes dependent on Stat5-GR interactions were preferentially enriched in functional groups related to growth and maturation. However, a small group of Stat5-responsive genes are not totally, but still partially, dependent on GR, including IGF-1 and ALS.

We show that the Stat5b $\mathrm{N}$ terminus is the docking domain for the GR, while it is not necessary for chromatin binding. Accordingly, it is required for the expression of the genes dependent on GR-Stat5 interactions in vivo and for normal postnatal growth. We have recently demonstrated that this domain is also important for the tetramerization of Stat5a (Moriggl et al. 2005). The AF-1 domain of GR may be its binding partner, since it has been shown to be necessary for the Stat5-GR interaction (Stoecklin et al. 1997).

In conclusion, we show an unexpectedly prominent role of GR acting as a coactivator of Stat5 in the liver. We provide in vivo evidence that this interaction is not an unselective requirement for all Stat 5 signaling but that it preferentially affects gene sets involved in growth and maturation. In line with this, we show that GR-Stat5 interactions in hepatocytes are instrumental for normal postnatal growth and that the coactivating action of GR involves the $\mathrm{N}$ terminus of Stat5. This provides insight into the mechanism of growth control, providing support for the challenged somatomedin hypothesis, which postulates a critical role for hepatic GH signaling in postnatal growth.

\section{Materials and methods}

Animals

Mice were housed according to international standard conditions and all animal experiments conformed to local and international guidelines for the use of experimental animals. GR ${ }^{\text {AlfpCre }}$ and Stat $5^{\Delta \mathrm{N}}$ mice were generated as previously described (Teglund et al. 1998; Tronche et al. 2004). Stat $5^{\text {AlfpCre }}$ mice were generated by crossing mice in which both the Stat5a and Stat5b genes were flanked by two loxP sites with mice expressing Cre recombinase under the control of the albumin/ $\alpha$-fetoprotein control sequences (Kellendonk et al. 2000; Cui et al. 2004). Livers for Affymetrix analysis were harvested at postnatal day 28 , shock-frozen in liquid nitrogen, and stored at $-80^{\circ} \mathrm{C}$. To determine body growth, we weighed animals every week. Mice were injected with GH or PBS as previously described (Tronche et al. 2004).

Microarrays and quantitative PCR

For each microarray, three livers were pooled. Total RNA was isolated using RNeasy kits with DNaseI digest on column (Qiagen). RNA quality was assessed using the Bioanalyzer 2100 Lab-on-chip system (Agilent Technologies). Ten micrograms of RNA were labeled and hybridized onto mouse U74Av2 arrays, containing 12,500 sequences. Quantitative 
PCR cDNA was performed using TaqMan reverse transcription reagents and gene expression assays.

\section{Expression profiling analysis}

We used three arrays for each mutant group (Stat5 ${ }^{\text {AlfpCre }}$, GR ${ }^{\text {AlfpCre }}$, Stat5/GR AlfpCre, and Stat5 ${ }^{\Delta \mathrm{N}}$ ) and nine arrays for the control group (littermates to the mutant mice). Arrays were normalized using GCRMA. Genes with a mean expression of $<25$ in all of the groups were excluded, leaving 5996 probe sets for the analysis. Significance levels were calculated in affylmGUI. As criterion for calling a gene significantly changed we used $p<0.001$, or the combined criterion of $p<0.0025$ and a $\log$ ratio $>1$ or less than -1 (fold change $>2$ or $<0.5$ ). Investigation of coordinated changes in functional gene sets was done using MAPPfinder. We limited the analysis to $\sim 100$ predefined groups, of which some where custom made. The two criteria for inclusion of genes were $p<0.01$ and $p<0.05$. Gene sets with $p$-value $<0.05$ after correction for multiple comparisons were considered significant.

\section{ChIP}

Nuclei were prepared from mouse liver, and chromatin was cross-linked, sonicated, and immunoprecipitated according to our previous protocol (Tronche et al. 2004). Chromatin fragments were immunoprecipitated with the anti-Stat5 (C17, Santa Cruz Biotechnology) polyclonal rabbit antibody (Santa Cruz Biotechnology). Quantitative PCR was carried out using a SYBR green kit (Applied Biosystems). ChIP DNA samples were analyzed in triplicates. Enrichment was normalized against a nonspecific background using a primer pair located downstream from the ALS 3'-end.

Western blotting, immunoprecipitation, and bandshift assays Blots were probed with rabbit polyclonal antibodies against Stat5b (epitope amino acids 775-788), P-Y-Stat5 (\#71-6900, Zymed), the C terminus of Stat5 (C17, Santa Cruz Biotechnolgy), the N terminus of GR (M20, Santa Cruz Bechnology), or a mouse monoclonal antibody against Stat5b (epitope amino acids 451-649; \#610190, BD Transduction Laboratory). Four individual mice in each group were analyzed. Bandshift assays on the $\beta$-casein promoter were carried out as described previously (Moriggl et al. 1996). Similar data were obtained in four individual experiments.

\section{Acknowledgments}

We are grateful to Ralf Klären and Tabea Arnsperger for technical assistance, to Milen Kirilov for providing RNA for the RT-PCR, to Monica Hollstein for providing access to the Affymetrix platform, and to Wolfgang Schmid for helpful discussions. This work was supported by EMBO (D.E.); FWF grant SFB F28 (to R.M., J.-W.K., and H.B.); FOR Ot 165/2-2; GRK 791/1.02; the European Union through grant LSHM-CT-2005018652 (CRESCENDO); the Bundesministerium für Bildung und Forschung (BMBF) through NGFN grants FZK 01GS01117, 01GS0477 and KGCV1/ 01GS0416; and project number 0313074C (Systems Biology).

\section{References}

Biola, A., Lefebvre, P., Perrin-Wolff, M., Sturm, M., Bertoglio, J., and Pallardy, M. 2001. Interleukin-2 inhibits glucocorticoid receptor transcriptional activity through a mechanism involving STAT5 (signal transducer and activator of transcription 5) but not AP-1. Mol. Endocrinol. 15: 1062-1076.

Chin, E., Zhou, J., Dai, J., Baxter, R.C., and Bondy, C.A. 1994. Cellular localization and regulation of gene expression for components of the insulin-like growth factor ternary binding protein complex. Endocrinology 134: 2498-2504.

Clodfelter, K.H., Holloway, M.G., Hodor, P., Park, S.H., Ray, W.J., and Waxman, D.J. 2006. Sex-dependent liver gene expression is extensive and largely dependent upon signal transducer and activator of transcription 5b (STAT5b): STAT5b-dependent activation of male genes and repression of female genes revealed by microarray analysis. Mol. Endocrinol. 20: 1333-1351.

Cui, Y., Riedlinger, G., Miyoshi, K., Tang, W., Li, C., Deng, C.X., Robinson, G.W., and Hennighausen, L. 2004. Inactivation of Stat5 in mouse mammary epithelium during pregnancy reveals distinct functions in cell proliferation, survival, and differentiation. Mol. Cell. Biol. 24: 8037-8047.

Doniger, S.W., Salomonis, N., Dahlquist, K.D., Vranizan, K., Lawlor,
S.C., and Conklin, B.R. 2003. MAPPFinder: Using Gene Ontology and GenMAPP to create a global gene-expression profile from microarray data. Genome Biol. 4: R7.

Hoelbl, A., Kovacic, B., Kerenyi, M.A., Simma, O., Warsch, W., Cui, Y., Beug, H., Hennighausen, L., Moriggl, R., and Sexl, V. 2006. Clarifying the role of Stat5 in lymphoid development and Abelson-induced transformation. Blood 107: 4898-4906.

Isaksson, O.G., Jansson, J.O., and Gause, I.A. 1982. Growth hormone stimulates longitudinal bone growth directly. Science 216: 1237-1239.

Kellendonk, C., Opherk, C., Anlag, K., Schutz, G., and Tronche, F. 2000. Hepatocyte-specific expression of Cre recombinase. Genesis 26: 151153.

Klover, P. and Hennighausen, L. 2007. Postnatal body growth is dependent on the transcription factors signal transducers and activators of transcription $5 \mathrm{a} / \mathrm{b}$ in muscle: A role for autocrine/paracrine insulinlike growth factor I.. Endocrinology 148: 1489-1497.

Moriggl, R., Gouilleux-Gruart, V., Jahne, R., Berchtold, S., Gartmann, C., Liu, X., Hennighausen, L., Sotiropoulos, A., Groner, B., and Gouilleux, F. 1996. Deletion of the carboxyl-terminal transactivation domain of MGF-Stat5 results in sustained DNA binding and a dominant negative phenotype. Mol. Cell. Biol. 16: 5691-5700.

Moriggl, R., Sexl, V., Kenner, L., Duntsch, C., Stangl, K., Gingras, S., Hoffmeyer, A., Bauer, A., Piekorz, R., Wang, D., et al. 2005. Stat5 tetramer formation is associated with leukemogenesis. Cancer Cell 7: 87-99.

Reichardt, H.M., Kaestner, K.H., Tuckermann, J., Kretz, O., Wessely, O., Bock, R., Gass, P., Schmid, W., Herrlich, P., Angel, P., et al. 1998. DNA binding of the glucocorticoid receptor is not essential for survival. Cell 93: 531-541.

Reichardt, H.M., Tuckermann, J.P., Gottlicher, M., Vujic, M., Weih, F., Angel, P., Herrlich, P., and Schutz, G. 2001. Repression of inflammatory responses in the absence of DNA binding by the glucocorticoid

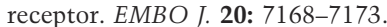

Rowland, J.E., Lichanska, A.M., Kerr, L.M., White, M., d'Aniello, E.M., Maher, S.L., Brown, R., Teasdale, R.D., Noakes, P.G., and Waters, M.J. 2005. In vivo analysis of growth hormone receptor signaling domains and their associated transcripts. Mol. Cell. Biol. 25: 66-77.

Sjogren, K., Liu, J.L., Blad, K., Skrtic, S., Vidal, O., Wallenius, V., LeRoith, D., Tornell, J., Isaksson, O.G., Jansson, J.O., et al. 1999. Liver-derived insulin-like growth factor I (IGF-I) is the principal source of IGF-I in blood but is not required for postnatal body growth in mice. Proc. Nat1. Acad. Sci. 96: 7088-7092.

Stocklin, E., Wissler, M., Gouilleux, F., and Groner, B. 1996. Functional interactions between Stat5 and the glucocorticoid receptor. Nature 383: 726-728.

Stoecklin, E., Wissler, M., Moriggl, R., and Groner, B. 1997. Specific DNA binding of Stat5, but not of glucocorticoid receptor, is required for their functional cooperation in the regulation of gene transcription. Mol. Cell. Biol. 17: 6708-6716.

Teglund, S., McKay, C., Schuetz, E., van Deursen, J.M., Stravopodis, D., Wang, D., Brown, M., Bodner, S., Grosveld, G., and Ihle, J.N. 1998. Stat5a and Stat5b proteins have essential and nonessential, or redundant, roles in cytokine responses. Cell 93: 841-850.

Tronche, F., Opherk, C., Moriggl, R., Kellendonk, C., Reimann, A., Schwake, L., Reichardt, H.M., Stangl, K., Gau, D., Hoeflich, A., et al. 2004. Glucocorticoid receptor function in hepatocytes is essential to promote postnatal body growth. Genes \& Dev. 18: 492-497.

Udy, G.B., Towers, R.P., Snell, R.G., Wilkins, R.J., Park, S.H., Ram, P.A., Waxman, D.J., and Davey, H.W. 1997. Requirement of STAT5b for sexual dimorphism of body growth rates and liver gene expression. Proc. Natl. Acad. Sci. 94: 7239-7244.

Yakar, S., Liu, J.L., Stannard, B., Butler, A., Accili, D., Sauer, B., and LeRoith, D. 1999. Normal growth and development in the absence of hepatic insulin-like growth factor I. Proc. Natl. Acad. Sci. 96: 7324-7329.

Yakar, S., Rosen, C.J., Beamer, W.G., Ackert-Bicknell, C.L., Wu, Y., Liu, J.L., Ooi, G.T., Setser, J., Frystyk, J., Boisclair, Y.R., et al. 2002. Circulating levels of IGF-1 directly regulate bone growth and density. J. Clin. Invest. 110: 771-781.

Yao, Z., Cui, Y., Watford, W.T., Bream, J.H., Yamaoka, K., Hissong, B.D., Li, D., Durum, S.K., Jiang, Q., Bhandoola, A., et al. 2006. Stat5a/b are essential for normal lymphoid development and differentiation. Proc. Natl. Acad. Sci. 103: 1000-1005. 


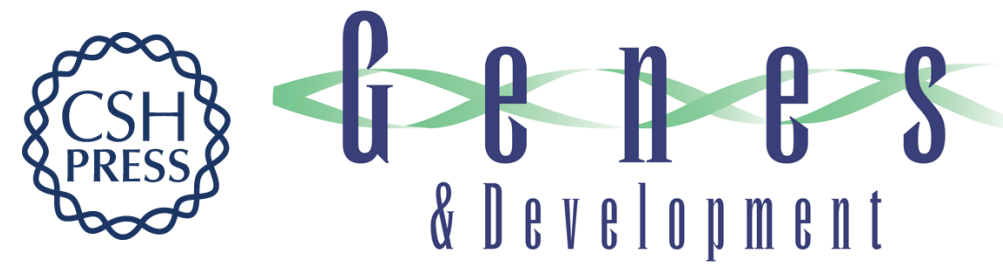

\section{Direct glucocorticoid receptor-Stat5 interaction in hepatocytes controls body size and maturation-related gene expression}

David Engblom, Jan-Wilhelm Kornfeld, Lukas Schwake, et al.

Genes Dev. 2007, 21:

Access the most recent version at doi:10.1101/gad.426007

Supplemental http://genesdev.cshlp.org/content/suppl/2007/04/30/21.10.1157.DC1
Material

References This article cites 23 articles, 12 of which can be accessed free at:

http://genesdev.cshlp.org/content/21/10/1157.full.html\#ref-list-1

License

Email Alerting Receive free email alerts when new articles cite this article - sign up in the box at the top

Service right corner of the article or click here.

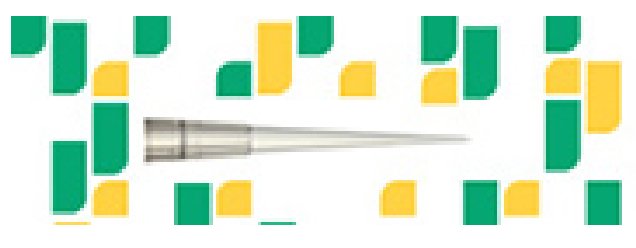

Focused on your science. 